\title{
CONCEPTUALIZATION AND PRELIMINARY VALIDATION OF A DEPRESSIVE PERSONALITY CONCEPT
}

\author{
Rui C. Campos, PhD \\ University of Évora
}

\begin{abstract}
This paper proposes a depressive personality organization-a unique set of traits. It proposes a psychodynamic and psychiatric operationalization and reports on a preliminary validation through the construction of a questionnaire and the investigation of its psychometric properties in three nonclinical samples and a clinical sample of depressed patients. Preliminary results support the validity of the instrument and the underlying theoretical conceptualization of a depressive personality.
\end{abstract}

Keywords: depressive personality, inventory, conceptual proposition, validation

The concept of depressive personality, akin to that of depression, has been discussed for many years in the psychiatric and psychoanalytic literature. It has been described and used by clinicians and researchers from several theoretical perspectives (Campos, 2009a; Phillips, Gunderson, Hirschfeld, \& Smith, 1990; Phillips, Hirschfeld, Shea, \& Gunderson, 1993; Ryder, Bagby, \& Schuler, 2002), particularly by psychodynamic clinicians and classic authors in German psychiatry (Klein \& Miller, 1997; Koldobsky, 2003). For Klein, Wonderlich, and Shea (1993), the concept of a depressive personality is at the crossroads between depression and personality because the two concepts merge into one. The depressed mood and the other depressive features are presented as chronic and stable personality traits; there is a depressive personality or character structure (see also Klein, Durbin, Shankman, \& Santiago, 2002).

Rui C. Campos, PhD, Department of Psychology and Research Center for Education and Psychology, University of Évora, Portugal.

I acknowledge the research assistants of the University of Évora, Portugal for their valuable help with data collection. Grateful thanks are also extended to all of the participants in this study. I thank Prof. Sidney Blatt for his important contributions to a previous version of this paper. I also wish to thank Prof. Bruno Gonçalves and Prof. Teresa Fagulha for their important assistance in the items development process.

Correspondence concerning this article should be addressed to Rui C. Campos, PhD, Department of Psychology, University of Évora, Apartado 94, Évora, Portugal 7002-554. E-mail: rcampos@uevora.pt 